\title{
RNA-Seq analysis for the potential targets and molecular mechanisms of $17 \beta$-estradiol in squamous cell lung carcinoma
}

\author{
X. CHEN* ${ }^{*}$ R. WU, S. WANG, Q. DUAN, Y. XUAN \\ Department of Medical Oncology, Shengjing Hospital of China Medical University, Shenyang, 110022, China \\ ${ }^{*}$ Correspondence: chenxdxdxd@hotmail.com
}

Received August 14, 2015 / Accepted December 23, 2015

\begin{abstract}
The efficacy of $17 \beta$-estradiol (E2) was valid in some cancers, while its effects on squamous cell lung carcinoma (SCLC) were still unclear. The aim of our study was to investigate the potential targets and molecular mechanisms of E2 in SCLC cells.

Two RNA libraries from human lung carcinoma cells (SK-MES-1) with and without E2 treatment were constructed and sequenced. The differentially expressed genes (DEGs) between cells with or without E2 treatment were identified by cuffdiff software. Hierarchical Clustering Analysis (HCA) was performed for displaying gene expression changes and classification. Furthermore, enrichment analyses of Kyoto Encyclopedia of Genes and Genomes (KEGG) pathway and Gene Ontology Biological Process (GO BP) terms were performed through DAVID. The protein-protein interaction (PPI) network was constructed through STRING. Additionally, differentially expressed lncRNAs were also selected by cuffdiff software.

Total 129 DEGs including 58 up- and 71 down- regulated genes were obtained. Cancer-related pathways including small cell lung cancer, hypertrophic cardiomyopathy (HCM) and pathways in cancer and biological processes including regulation of phosphorus metabolic process, protein localization and nucleus organization were enriched. The PPI network with 113 nodes and 312 edges was constructed. CASP3, ITGA2, COL4A6, PML and CDC25B were identified as hub nodes which had more interactions with others in the PPI network. Furthermore, eight up-regulated and ten down-regulated lncRNAs were selected.

CASP3, ITGA2 and Lnc-DLK1-4:31 (one of down-regulated lncRNAs) might play pivotal roles in E2 treated SCNC cells by influencing cell apoptosis, angiogenesis and cell invasion respectively.
\end{abstract}

Key words: squamous cell lung carcinoma, RNA-Seq, differentially expressed genes, Inc-RNA

Squamous cell lung carcinoma (SCLC) is a common type of non-small-cell lung cancer (NSCLC) and the second leading cause of death related to lung cancer which causes approximately 400,000 deaths per year worldwide [1]. SCLC develops mainly in the upper airways and cigarette smokers are more susceptible to SCLC, therefore it is more common in men than in women [2]. Although various therapies such as radiation, chemotherapy, surgery and palliative care have been used for SCLC treatment, the overall therapeutic results were not optimistic [3, 4]. A more thorough understanding of the mechanism of SCLC may offer a new hope on treatment innovations and prevention strategies.

Estrogens are a group of human sex hormones which can be secreted primarily by the ovaries and placenta in women and the testes in men. The cell response to estrogens is in a concentration-dependent manner. Previous studies found that low concentration of $17 \beta$-estradiol (E2) promoted the development of breast cancer and prostatic cancer, while $10 \mathrm{nM}$ or higher concentration of E2 could cause cancer cell apoptosis [5-7]. The three major naturally occurring estrogens are $\mathrm{E} 2$, estrone and estriol, among them, $\mathrm{E} 2$ is the predominant and most active [8]. Meanwhile, Zhao et al. certified that E2 treatment could inhibite breast cell invasion and migration in an estrogen receptor $\alpha(E R \alpha)$-independent way by decreasing MALAT-1 RNA level [9]. Coincidentally, estrogen receptors are also reported to play a key role in the progression of various types of NSCLC including adenocarcinoma (ADCA), SCLC, and large-cell carcinoma [10]. Moreover, the clinical and biological significances of estrogen metabolisms has been studied in NSCLCs and they might play critical roles in regulating lung cancer biology [11]. However, effects of E2 on the progression of NSCLC, especially for SCLC, have not been adequately studied and whether E2 could be a candidate treatment for SCLC was rarely studied. 
The development of RNA-Seq has become increasingly important in cancer research and RNA-Seq has been employed in the study of certain type cancers such as prostate cancer, breast cancers and liver cancer. Some novel mechanisms of these cancers genesis and progression have been found with this method [12-15]. In the present study, we aimed to explore the targets and potential molecular mechanisms of E2 in SCLC cells using RNA-Seq and bioinformatics analysis, in order to provide theoretical basis for the treatment of SCLC by E2. Our study might also put forward some new insights for the molecular mechanism of E2 treatment on SCLC and supply some potential targets for lung cancer treatment.

\section{Materials and methods}

Cell line and cell culture. The human lung carcinoma cell line SK-MES-1 was purchased from the Cell Bank of Type Culture Collection of Chinese Academy of Sciences (Shanghai, China). The cell line was cultivated in Dulbecco's modified Eagles medium (DMEM, GIBCO BRL, Gaithersburg, MD, USA) supplemented with $10 \%$ fetal bovine serum (FBS, GIBCO BRL, Gaithersburg, MD, USA), $100 \mathrm{IU} / \mathrm{ml}$ penicillin and $100 \mu \mathrm{g} / \mathrm{mL}$ streptomycin in a humidified $37^{\circ} \mathrm{C}$ incubator containing $5 \% \mathrm{CO}_{2}[16]$.

Grouping and cell treatment. Two groups were set up for the study, including E2 group and control group. The cells in E2 group were exposure to E2 (Sigma-Aldrich, St. Louis, MO, USA), which was dissolved in dimethylsulfoxide (DMSO, Sigma-Aldrich, St. Louis, MO, USA), at the concentration of $15 \mathrm{umol} / \mathrm{L}$ for 48 hours. Meanwhile, equal volume of DMSO was used in the control group.

RNA isolation. Total RNA was extracted from the cells untreated and treated with E2 using Trizol reagent (GIBCO BRL, Gaithersburg, MD, USA) according to the manufacturer's instructions [17]. The integrity of RNA was detected by $1 \%$ agarose gel electrophoresis and the RNA concentration was determined by using an ultraviolet spectrophotometry (Cary 50, Varian, USA).

RNA library construction and sequencing. RNA-Seq libraries were prepared from a total of $5 \mu \mathrm{g}$ RNA using the NEBNext ${ }^{\circledR}$ Ultra RNA Library Prep Kit for Illumina ${ }^{\oplus}$ (New England Biolabs, Ipswich, MA, U.S.A.) [18]. Briefly, RNA was fragmented into approximately $200 \mathrm{nt}$ fragments. Then double-stranded cDNA was synthesized and the cDNA was end-repaired before ligation of Illumina-specific adaptors. Finally, PCR amplification was performed to obtain cDNA library. After assessing the library quality on a Bioanalyzer ${ }^{\circledR}$ (Agilent Technologies, Santa Clara, CA, U.S.A.), RNA sequencing was performed using an Illumina HiSeq 2500 (100 base paired ends) [19]. Data analysis was performed using the HiSeq Analysis Software (Illumina) to generate sequence data in FASTQ format.

Mapping RNA-Seq reads to reference genome. High quality data were obtained from raw data by removing reads with $\mathrm{N}$ content more than $3 \%$ and low-quality reads ( $\mathrm{Q}$ value of $\leq$ 18) more than $50 \%$. The TopHat2 software [20] was utilized to map the high quality clean reads to the reference human genome (hg19) with default parameters. Genomics and refseq annotation files were obtained from UCSC (http://genome.ucsc.edu/).

Screening differently expressed genes (DEGs). Cuffdiff [21] was employed for the calculation of gene expression levels of annotated genes and the screening of the DEGs between E2 and control group with cut-off criteria of $p$-value $<0.001$ and | $\log _{2}$ Fold Change (FC) $\mid>1$. Meanwhile, heatmap was utilized to visually display the characteristic gene expression changes among different samples by Hierarchical Cluster Analysis (HCA) using gplots package in R.

Pathway and functional enrichment analyses. Enrichment analyses of Kyoto Encyclopedia of Genes and Genomes (KEGG) pathway and Gene Ontology Biological Process (GO BP) terms were performed with R package Goseq [22] to identify significantly enriched pathways and the biological processes of the DEGs, using the online tool of the database for annotation, visualization and integrated discovery (DAVID, http://david. abcc.ncifcrf.gov/) [23] with the $p$-value $<0.05$.

PPI network construction. DEGs were submitted to Search Tool for the Retrieval of Interacting Genes (STRING) [24]. All interactions in STRING were provided with a probabilistic confidence score (combined score), and only interactions with combined score $>0.9$ were retained in our analysis. Then the PPI network was constructed and visualized with the Cytoscape software [25].

Differential long non-coding RNAs (lncRNAs) analysis. The expression values of $\operatorname{lncRNAs}$ were determined based on the search results on LNCipedia 3.0 database [26]. Afterwards, the differentially expressed lncRNAs were screened using Cuffdiff software [21] with the threshold of $p$-value $<0.01$ and $|\log \mathrm{FC}|>1$.

\section{Results}

DEG between E2 and control group. A total of 129 DEGs were identified, including 58 up-regulated genes and 71 downregulated genes. The scatter plot of gene expression levels is shown in Figure 1. Besides, the top 5 up-regulated genes and down-regulated genes at $\mathrm{p}$-Value are listed in Table 1 ,

Table 1. The top 5 up-regulated genes and down-regulated genes at $p$-Value

\begin{tabular}{lccc}
\hline & Gene & $\log _{2} \mathrm{FC}$ & $p$-Value \\
\hline Up-regulated genes & SLC35A3 & $1.79769 \mathrm{e}+308$ & $4.08 \mathrm{E}-13$ \\
& DLD & $1.79769 \mathrm{e}+308$ & $5.52 \mathrm{E}-08$ \\
& SCMH1 & $1.79769 \mathrm{e}+308$ & $1.72 \mathrm{E}-07$ \\
& PLEKHG5 & $1.79769 \mathrm{e}+308$ & $5.26 \mathrm{E}-07$ \\
& TLE3 & $1.79769 \mathrm{e}+308$ & $6.56 \mathrm{E}-06$ \\
Down-regulated genes & SPAG9 & -1.61518 & $3.83 \mathrm{E}-13$ \\
& SLC9A8 & $-1.79769 \mathrm{e}+308$ & $3.01 \mathrm{E}-12$ \\
& PRKAA1 & $-1.79769 \mathrm{e}+308$ & $1.29 \mathrm{E}-09$ \\
& JKAMP & $-1.79769 \mathrm{e}+308$ & $4.90 \mathrm{E}-08$ \\
& PAM & $-1.79769 \mathrm{e}+308$ & $8.78 \mathrm{E}-07$ \\
\hline
\end{tabular}

E2: $17 \beta$-estradiol; FC: Fold Change 


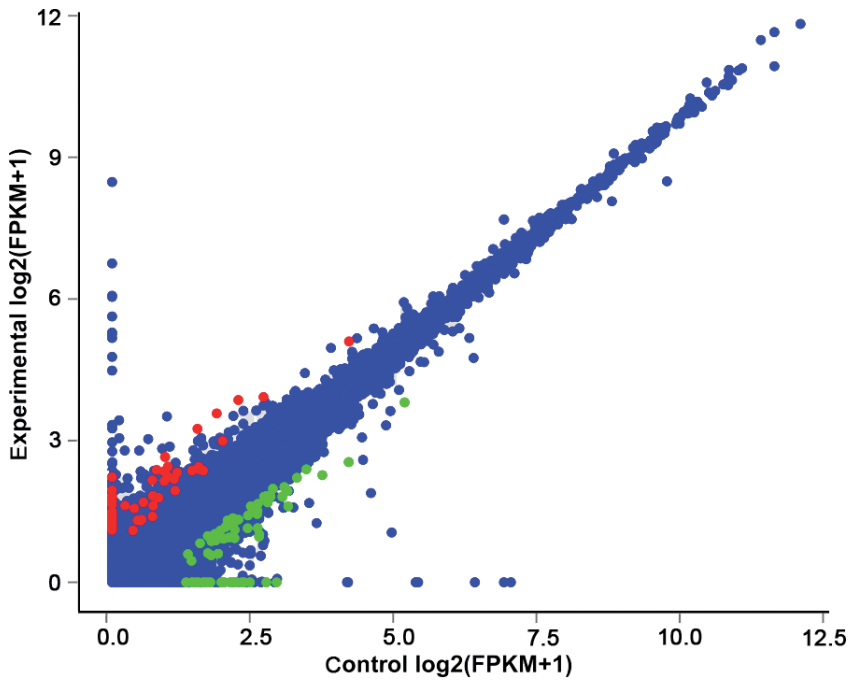

Figure 1. The scattergram for gene expression levels. Red, green and blue nodes represented for the up-regulated DEGs, down-regulated DEGs and non-DEGs respectively. Abscissa represented for the control group and ordinate represented for the experimental group which was treated by 17 $\beta$-estradiol. DEGs: differentially expressed genes.

respectively. Meanwhile, HCA result also showed that the expression pattern of the characteristic gene set could well distinguish control and E2 samples (Figure 2). From the heat map, the 129 genes could be divided into two clusters. Overall, compared with control samples, the expression of genes in the cluster-1 was higher in E2 samples, whereas the expression of genes in the cluster-2 was lower in E2 samples.
KEGG pathway and GO BP enrichment analyses. All the enriched KEGG terms and top 10 GO BP terms are listed in Table 2 and 3. Three pathways including small cell lung cancer, hypertrophic cardiomyopathy (HCM) and pathways in cancer were enriched according to the KEGG enrichment analysis. ITGA2 was identified in the pathway of SCLC and CASP3 and ITGA2 were both involved in pathways in cancer (Table 2). For the GO BP terms, processes including regulation of phosphorus metabolic process, protein localization, nucleus organization and apoptosis were significantly enriched and CASP3 and ITGA2 were also identified in the regulation of phosphorus metabolic process (Table 3).

PPI network of DEGs. The PPI network including 113 nodes and 312 interactions was constructed (Figure 2). The connectivity degree of each node in this PPI network was calculated and the top 5 nodes with degree $\geq 10$ were CASP3 (caspase-3), ITGA2 (integrin alpha-2, also named collagen receptor or CD49 antigen-like family member B), COL4A6 (collagen alpha-6(IV) chain), PML (promyelocytic leukemia protein) and CDC25B (M-phase inducer phosphatase 2).

Differentially expressed lncRNAs. Totally, 18 differentially expressed lncRNAs were identified between E2 and control group, including eight up-regulated lncRNAs and ten down-regulated lncRNAs. The detailed information of these differentially expressed lncRNAs is listed in Table 4.

\section{Discussion}

Currently, SCLC is still a malignant lung tumor and seriously threatens human life. Therefore, it is urgent to explore the mechanism and develop effective prevention strategies for

Table 2. The enriched KEGG pathway of the differentially expressed genes

\begin{tabular}{lccc}
\hline KEGG pathway & Count & $p$-Value & Genes \\
\hline Small cell lung cancer & 4 & 0.008596 & LAMA4, ITGA2, COL4A6, TRAF3 \\
Hypertrophic cardiomyopathy (HCM) & 4 & 0.00888 & DMD, CACNG6, ITGA2, PRKAA1 \\
Pathways in cancer & 6 & 0.023173 & LAMA4, CASP3, PML, ITGA2, COL4A6, TRAF3 \\
\hline
\end{tabular}

KEGG: Kyoto Encyclopedia of Genes and Genomes; Count stands for the number of differentially expressed genes.

Table 3. Gene Ontology Biological Process enrichment analysis of the differentially expressed genes (Top 10 by $p$-value)

\begin{tabular}{llcc}
\hline GO ID & Term & Count & $p$-Value \\
\hline GO:0051174 & regulation of phosphorus metabolic process & 10 & 0.0042178 \\
GO:0019220 & regulation of phosphate metabolic process & 10 & 0.0042178 \\
GO:0008104 & protein localization & 14 & 0.00445 \\
GO:0006997 & nucleus organization & 4 & 0.0046707 \\
GO:0006915 & apoptosis & 11 & 0.0056114 \\
GO:0012501 & programmed cell death & 11 & 0.0062136 \\
GO:0045859 & regulation of protein kinase activity & 8 & 0.0071658 \\
GO:0043549 & regulation of kinase activity & 8 & 0.0085718 \\
GO:0046907 & intracellular transport & 11 & 0.0101228 \\
GO:0051338 & regulation of transferase activity & 8 & 0.0106039 \\
\hline
\end{tabular}

Count stands for the number of differentially expressed genes. 


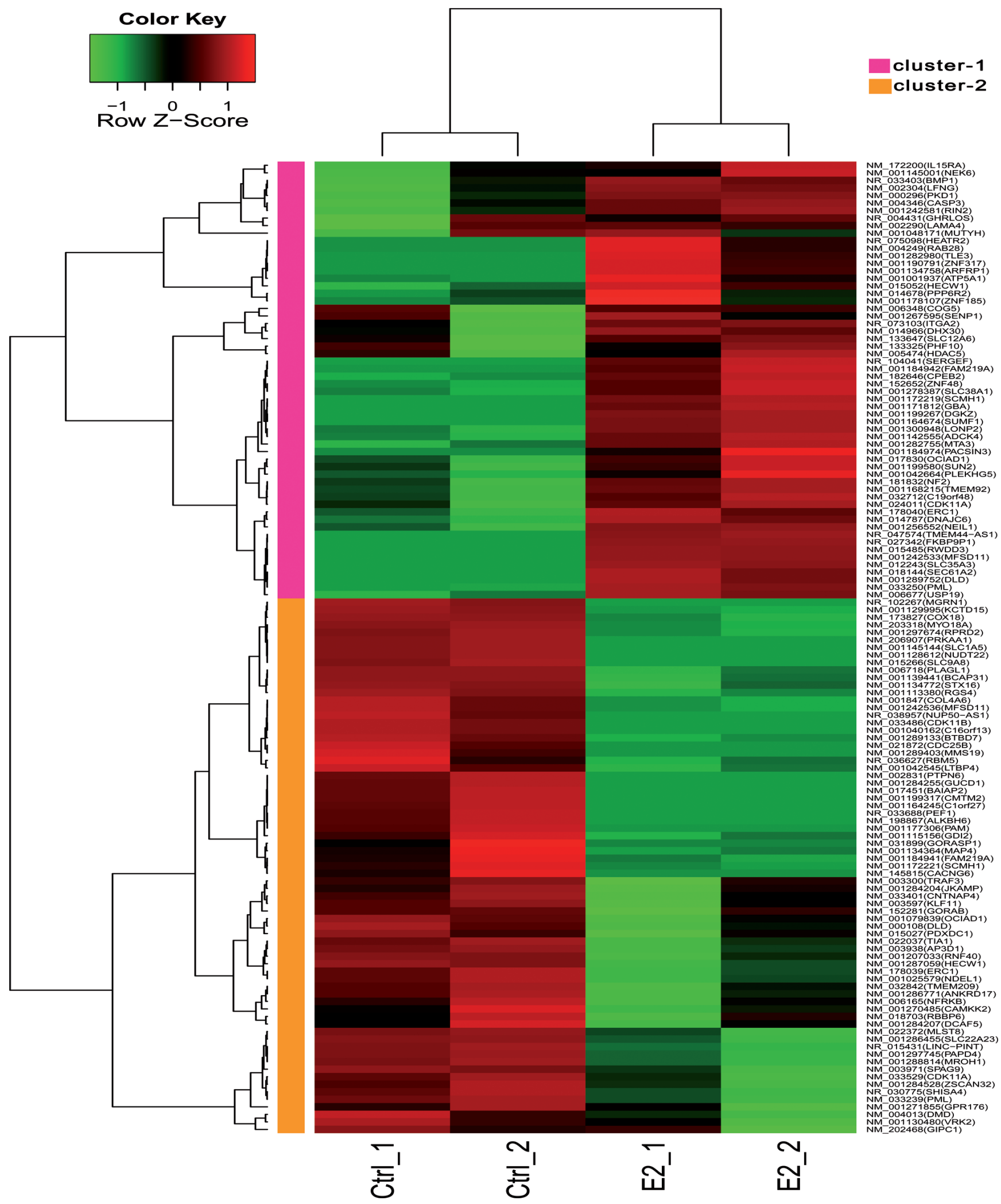

Figure 2. Hierarchical Clustering Analysis (HCA) for the differentially expressed genes (DEGs). Two clusters were marked with different colors in the left of the figure. Pink represents cluster-1 and genes in which were up-regulated in (E2) group; orange represents cluster-2 and genes in which were down-regulated in E2 group. Ctrl: control group; E2: $17 \beta$-estradiol group. 


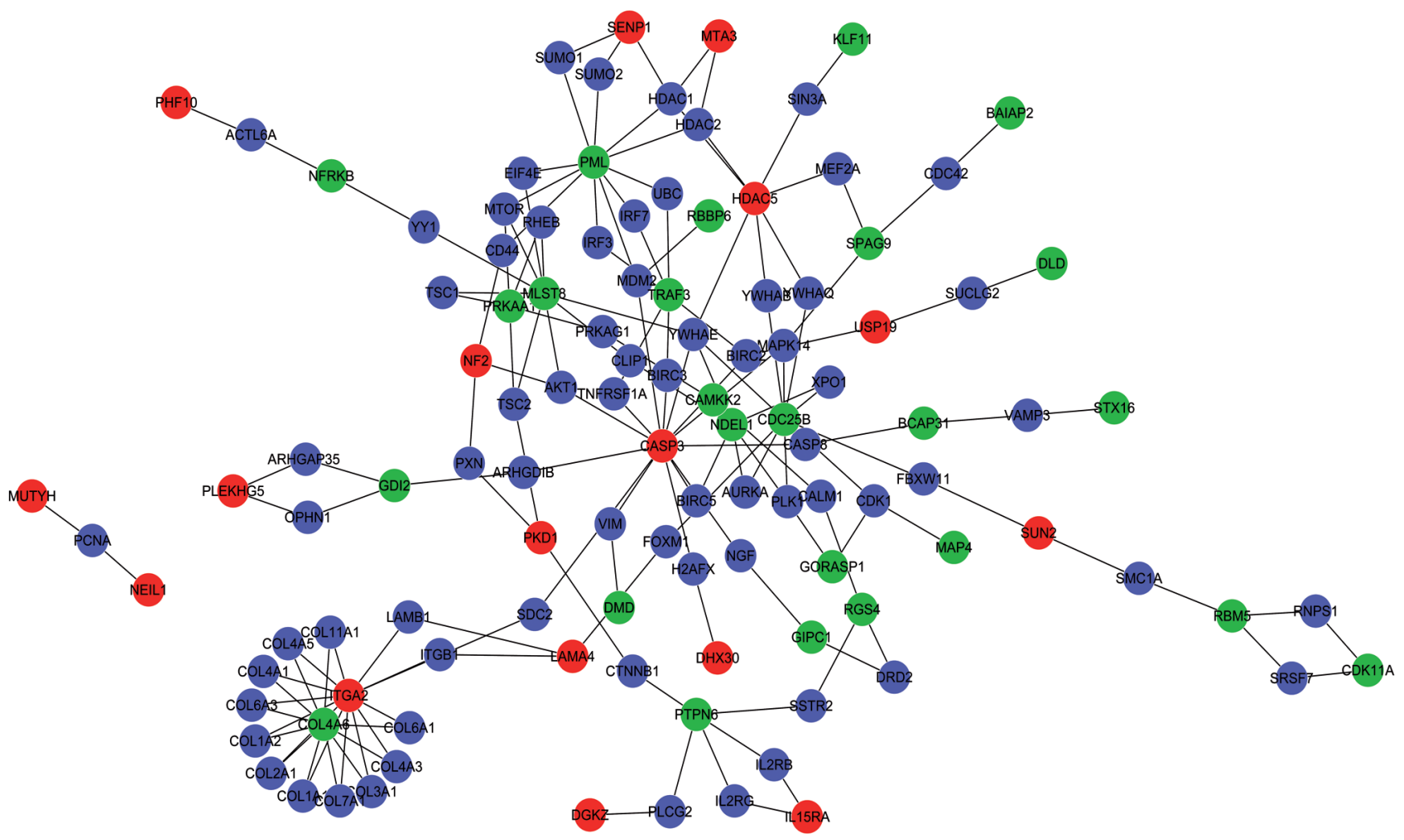

Figure 3. The protein-protein interaction network. Red, green and blue nodes represented for the up-regulated DEGs, down-regulated DEGs and nondifferentially expressed genes respectively. DEGs: differentially expressed genes.

Table 4. Differentially expressed IncRNAs

\begin{tabular}{|c|c|c|c|}
\hline & $\operatorname{lncRNAs}$ & $\log _{2} \mathrm{FC}$ & $p$-Value \\
\hline \multirow[t]{8}{*}{$\begin{array}{l}\text { Up-regulated } \\
\text { lncRNAs }\end{array}$} & $\operatorname{lnc}-\mathrm{CNN} 3-3: 1$ & 1.20405 & 0 \\
\hline & lnc-IL15RA-2:3 & $1.79769 \mathrm{e}+308$ & $1.48 \mathrm{E}-08$ \\
\hline & lnc-KIAA1257-3:1 & 3.49229 & $1.86 \mathrm{E}-07$ \\
\hline & lnc-FAM138A-8:6 & $1.79769 \mathrm{e}+308$ & $2.02 \mathrm{E}-05$ \\
\hline & lnc-CD38-2:8 & $1.79769 \mathrm{e}+308$ & 0.000194 \\
\hline & lnc-R3HDM1-1:1 & $1.79769 \mathrm{e}+308$ & 0.000724 \\
\hline & lnc-LTC4S-2:1 & $1.79769 \mathrm{e}+308$ & 0.005308 \\
\hline & lnc-AC091132.1-3:2 & 1.34725 & 0.002519 \\
\hline \multirow[t]{10}{*}{$\begin{array}{l}\text { Down-regulated } \\
\text { lncRNAs }\end{array}$} & lnc-AC022098.1-1:2 & $-1.79769 e+308$ & $2.45 \mathrm{E}-07$ \\
\hline & lnc-IL15RA-2:2 & $-1.79769 e+308$ & $1.08 \mathrm{E}-06$ \\
\hline & lnc-AC103810.1-3:1 & -4.55604 & 0.000432 \\
\hline & $\operatorname{lnc}-\mathrm{CHD} 1-1: 2$ & $-1.79769 e+308$ & 0.000479 \\
\hline & lnc-DLK1-4:31 & $-1.79769 e+308$ & 0.000791 \\
\hline & lnc-ENOSF1-4:1 & -1.03183 & 0.002357 \\
\hline & lnc-RNF39-4:12 & $-1.79769 e+308$ & 0.004232 \\
\hline & lnc-CALCOCO2-8:26 & $-1.79769 e+308$ & 0.004349 \\
\hline & lnc-SENP5-2:6 & $-1.79769 e+308$ & 0.007809 \\
\hline & lnc-RP11-382B18.2.1-2:3 & -1.63184 & 0.008066 \\
\hline
\end{tabular}

E2: $17 \beta$-estradiol; FC: Fold Change.
SCLC. E2 has been confirmed to play a critical role in many cancers including SCLC. In the present study, we studied the comprehensive regulatory mechanisms of E2 in human lung carcinoma cell line SK-MES-1 with RNA-Seq. As a result, a total of 129 DEGs between E2 and control group were screened out. In the constructed PPT network, the top 5 nodes, namely CASP3, ITGA2, COL4A6, PML and CDC25B, were selected as hub nodes with high degrees. Besides, a total of 18 differentially expressed lncRNAs were identified.

CASP3 (encoding caspase-3), as an up-regulated gene in E2 group, was enriched in pathways in cancer and some biological processes mainly including regulation of phosphorus metabolic process, regulation of phosphate metabolic process, nucleus organization and apoptosis. In addition, the PPI network in our study showed that $C A S P 3$ directly interacted with BIRC2, BIRC3 and BIRC5. CASP3 (also known as CPP32, YAMA, or apopain) is the family member of caspases which is probably the one that so far best correlates with apoptosis $[27,28]$. Previous studies have shown that activation of CASP3 can be regulated by the Inhibitors of Apoptosis Proteins (IAPs) which share a common domain known as BIR (baculovirus IAP repeat), that binds to and inhibits CASP3 $[29,30]$. BIRC2 (previously known as c-IAP2), BIRC3 (previously known as c-IAP1) and BIRC5 (previously known as Survivin) are family members of IAP [31]. Studies have indicated that BIRC5 
contributes to tumourigenesis and progression of NSCLCs due to its apoptosis suppression functions [32,33]. Moreover, it has been reported that E2 can cause cancer cell apoptosis [34]. Therefore, we speculated that cell apoptosis was enhanced in SCNC after E2 treatment by up-regulating expression of CASP 3 and affecting the relationship between CASP 3 and IAP members (BIRC2, BIRC3 and BIRC5).

ITGA2 was also a hub node and interacted with 14 proteins in the PPI network. Previous study has indicated that ITGA2 encoding the $\alpha$-subunit of integrin $\alpha_{2} \beta_{1}$, which plays an important role in cancer development [35]. The expression of integrin $\alpha_{2} \beta_{1}$ is associated with motility, invasiveness and cellular differentiation of a variety of tumors [36]. Additionally, the overexpression of collagen receptor integrin such as $\alpha_{2} \beta_{1}$ in tumor cells has been reported to play a role in angiogenesis which was increased in NSCLC $[37,38]$. However, controversial effects of ITGA2 on cancer metastasis are proposed by several studies recently. Ding et al. has been reported that knocking down of ITGA2 could stimulate cancer cell migration but did not affect the invasion process, and down-regulation of ITGA2 induced primary cancer cell migration by regulating deploymerization of cytoskeleton and detaching the cell-cell adhesion [39]. There were also some literatures reported that ITGA2 was up-regulated in human lung squamous cell carcinoma after anti-cancer drugs treatment, such as curcumin [40]. So up-regulation of ITGA2 might be involved in the migration process in SCLC after treated by E2. The relationships between ITGA2 and some members of collagen family (COL6A3, COL6A1, COL3A1, COL2A1, COL1A2, COL1A1, COL4A3, COL4A5 and COL7A1) were also seen in the PPI network. Collagen structure plays a critical role in controlling tumor microenvironment which is important in the tumor angiogenesis progression according to previous researches [41]. Collagens including collagen Types I, III are found in vascular tissues and induce thrombosis in arteries and veins by influencing the angiogenesis progression [42]. Moreover, type I collagen can accelerate the angiogenesis process of hydrogel bioengineered tumors by tumor-endothelial cell co-culture in vitro [43]. Therefore, it was reasonable to suspect that the relationship between ITGA2 and collagen family might play a pivotal role in the $\mathrm{E} 2$ treatment for $\mathrm{SCNC}$ and the angiogenesis process might be involved.

In addition, Lnc-DLK1-4:31 was one of the significantly down-regulated lncRNAs in E2 group. Delta-Like 1 Homolog (DLK1) belongs to the EGF-like family and plays important roles in regulating cell differentiation [44]. Studies on DLK1 have revealed its abnormal expression in a variety of tumors, including glioma, hepatocellular carcinoma and lung cancer $[45,46]$. Increasing evidences revealed that the overexpression of $D L K 1$ could accelerate the proliferation of lung cancer cells and DLK1 could promote lung cancer cell invasion depending on Notch signaling [47]. Thus, E2 might inhibit SCLC cell invasion by down-regulating lnc-DLK1-4:31 to suppress the expression of $D L K 1$.

\section{Conclusion}

In conclusion, CASP3, ITGA2, and Lnc-DLK1-4:31 might play pivotal roles in $\mathrm{E} 2$ treated $\mathrm{SCNC}$ cells by influencing cell apoptosis, angiogenesis and cell invasion respectively. This study confirmed that E2 could be considered as potential treatment for SCLC and the analysis results might provide some molecular mechanisms for E2 as a treatment. However, further experiments should be conducted to confirm the expression changes of the key DEGs. For further investigating the effects of these hub nodes and LncRNAs on the SCLC treated by E2, more experiments in vivo and vitro are required in the future.

\section{References}

[1] MANTRIPRAGADA K, KHURSHID H. Targeting genomic alterations in squamous cell lung cancer. Front Oncol 2013; 3: 195. http://dx.doi.org/10.3389/fonc. 2013.00195

[2] XU C, FILLMORE CM, KOYAMA S, WU H, ZHAO Y, et al. Loss of Lkb1 and Pten leads to lung squamous cell carcinoma with elevated PD-L1 expression. Cancer Cell 2014; 25: 590-604. http://dx.doi.org/10.1016/j.ccr.2014.03.033

[3] RIDGE CA, MCERLEAN AM, GINSBERG MS. Epidemiology of lung cancer. Semin Intervent Radiol 2013; 30: 93-98. http://dx.doi.org/10.1055/s-0033-1342949

[4] OUYANG W-W, SU S-F, HU Y-X, LU B, MA Z, et al. Radiation dose and survival of patients with stage IV non-small cell lung cancer undergoing concurrent chemotherapy and thoracic three-dimensional radiotherapy: reanalysis of the findings of a single-center prospective study. BMC Cancer 2014; 14: 491. http://dx.doi.org/10.1186/1471-2407-14-491

[5] YU S, ZHANG Y, YUEN M-T, ZOU C, DANIELPOUR D, et al. 17-Beta-estradiol induces neoplastic transformation in prostatic epithelial cells. Cancer Lett 2011; 304: 8-20. http:// dx.doi.org/10.1016/j.canlet.2011.01.003

[6] SINGH KP, TREAS J, TYAGI T, GAO W. DNA demethylation by 5-aza-2-deoxycytidine treatment abrogates 17 betaestradiol-induced cell growth and restores expression of DNA repair genes in human breast cancer cells. Cancer Lett 2012; 316: 62-69. http://dx.doi.org/10.1016/j.canlet.2011.10.022

[7] SONG RX, SANTEN RJ, KUMAR R, ADAM L, JENG MH, et al. Adaptive mechanisms induced by long-term estrogen deprivation in breast cancer cells. Mol Cell Endocrinol 2002; 193: 29-42. http://dx.doi.org/10.1016/S0303-7207(02)00093-X

[8] RESANOVIC I, RIZZO M, ZAFIROVIC S, BJELOGRLIC P, PEROVIC M, et al. Anti-atherogenic Effects of $17 \beta$ Estradiol. Horm Metab Res 2013; 45: 701-708. http://dx.doi. org/10.1055/s-0033-1343478

[9] ZHAO Z, CHEN C, LIU Y, WU C. 17beta-Estradiol treatment inhibits breast cell proliferation, migration and invasion by decreasing MALAT-1 RNA level. Biochem Biophys Res Commun 2014; 445: 388-393. http://dx.doi.org/10.1016/j. bbrc.2014.02.006

[10] KAZMI N, M RQUEZ-GARB N DC, AIVAZYAN L, HAMILTON N, GARON EB, et al. The role of estrogen, progesterone 
and aromatase in human non-small-cell lung cancer. Lung Cancer Manage 2012; 1: 259-272. http://dx.doi.org/10.2217/ $\underline{\operatorname{lmt} .12 .44}$

[11] VERMA MK, MIKI Y, ABE K, SUZUKI T, NIIKAWA H, et al. Intratumoral localization and activity of 17beta-hydroxysteroid dehydrogenase type 1 in non-small cell lung cancer: a potent prognostic factor. J Transl Med 2013; 11: 167. http:// dx.doi.org/10.1186/1479-5876-11-167

[12] OZSOLAK F, MILOS PM. RNA sequencing: advances, challenges and opportunities. Nat Rev Genet 2010; 12: 87-98. http://dx.doi.org/10.1038/nrg2934

[13] SHAH SP, ROTH A, GOYA R, OLOUMI A, HA G, et al. The clonal and mutational evolution spectrum of primary triplenegative breast cancers. Nature 2012; 486: 395-399. http:// dx.doi.org/10.1038/nature10933

[14] PFLUEGER D, TERRY S, SBONER A, HABEGGER L, ESGUEVA R, et al. Discovery of non-ETS gene fusions in human prostate cancer using next-generation RNA sequencing. Genome Res 2011; 21: 56-67. http://dx.doi.org/10.1101/ gr. 110684.110

[15] HO DW, YANG ZF, YI K, LAM CT, NG MN, et al. Gene expression profiling of liver cancer stem cells by RNA-sequencing. PloS One 2012; 7: e37159. http://dx.doi.org/10.1371/journal. pone.0037159

[16] LIU B, PENG X-C, ZHENG X-L, WANG J, QIN Y-W. MiR126 restoration down-regulate VEGF and inhibit the growth of lung cancer cell lines $<\mathrm{i}>$ in vitro $</ \mathrm{i}>$ and $<\mathrm{i}>$ in vivo $</ \mathrm{i}>$. Lung Cancer 2009; 66: 169-175. http://dx.doi.org/10.1016/j. lungcan.2009.01.010

[17] NAM S-I, KWON T-K. Dexamethasone Inhibits Interleukin$1 \beta$-Induced Matrix Metalloproteinase-9 Expression in Cochlear Cells. Clin Exp Otorhinolar2014; 7: 175-180. http:// dx.doi.org/10.3342/ceo.2014.7.3.175

[18] MINAMI-FUKUDA F, NAGAI M, TAKAI H, MURAKAMI T, OZAWA T, et al. Detection of Bovine Group A Rotavirus Using Rapid Antigen Detection Kits, RT-PCR and NextGeneration DNA Sequencing. J Vet Med Sci 2013; 75: 1651. http://dx.doi.org/10.1292/jvms.13-0265

[19] LEUNG A, PARKS BW, DU J, TRAC C, SETTEN R, et al. Open chromatin profiling in mice livers reveals unique chromatin variations induced by high fat diet. J Biol Chem 2014; 289: 23557-23567. http://dx.doi.org/10.1074/jbc. M114.581439

[20] KIM D, PERTEA G, TRAPNELL C, PIMENTEL H, KELLEY $\mathrm{R}$, et al. TopHat2: accurate alignment of transcriptomes in the presence of insertions, deletions and gene fusions. Genome Biol 2013; 14: R36. http://dx.doi.org/10.1186/gb-2013-14-4$\underline{\mathrm{r} 36}$

[21] TRAPNELL C, WILLIAMS BA, PERTEA G, MORTAZAVI A, KWAN G, et al. Transcript assembly and quantification by RNA-Seq reveals unannotated transcripts and isoform switching during cell differentiation. Nat Biotechnol 2010; 28: 511-515. http://dx.doi.org/10.1038/nbt.1621

[22] YOUNG MD, WAKEFIELD MJ, SMYTH GK, OSHLACK A. Gene ontology analysis for RNA-seq: accounting for selection bias. Genome Biol 2010; 11: R14. http://dx.doi.org/10.1186/ gb-2010-11-2-r14
[23] HUANG DA W, SHERMAN BT, LEMPICKI RA. Systematic and integrative analysis of large gene lists using DAVID bioinformatics resources. Nat Protoc 2009; 4: 44-57. http://dx.doi. org/10.1038/nprot.2008.211

[24] FRANCESCHINI A, SZKLARCZYK D, FRANKILD S, KUHN M, SIMONOVIC M, et al. STRING v9.1: proteinprotein interaction networks, with increased coverage and integration. Nucleic Acids Res 2012; 41: D808-D815. http:// dx.doi.org/10.1093/nar/gks1094

[25] KOHL M, WIESE S, WARSCHEID B, Cytoscape: software for visualization and analysis of biological networks, in Data Mining in Proteomics. 2011, Springer. p. 291-303. http:// dx.doi.org/10.1007/978-1-60761-987-1_18

[26] VOLDERS P-J, HELSENS K, WANG X, MENTEN B, MARTENS L, et al. LNCipedia: a database for annotated human lncRNA transcript sequences and structures. Nucleic Acids Res2013; 41: D246-D251. http://dx.doi.org/10.1093/nar/ gks915

[27] NICHOLSON DW, ALI A, THORNBERRY NA, VAILLANCOURT JP, DING CK, et al. Identification and inhibition of the ICE/CED-3 protease necessary for mammalian apoptosis. Nature 1995; 376: 37-43. http://dx.doi. org/10.1038/376037a0

[28] FERNANDES-ALNEMRI T, LITWACK G, ALNEMRI ES. CPP32, a novel human apoptotic protein with homology to Caenorhabditis elegans cell death protein Ced-3 and mammalian interleukin-1 beta-converting enzyme. J Biol Chem 1994; 269: 30761-30764.

[29] CLEM RJ, MILLER LK. Control of programmed cell death by the baculovirus genes p35 and iap. Mol Cell Biol 1994; 14: 5212-5222. http://dx.doi.org/10.1128/MCB.14.8.5212

[30] LISTON P, FONG WG, KORNELUK RG. The inhibitors of apoptosis: there is more to life than Bcl2. Oncogene 2003; 22: 8568-8580. http://dx.doi.org/10.1038/sj.onc.1207101

[31] VAUX DL, SILKE J. IAPs, RINGs and ubiquitylation. Nat Rev Mol Cell Biol 2005; 6: 287-297. http://dx.doi.org/10.1038/ $\underline{\text { nrm } 1621}$

[32] LU B, MU Y, CAO C, ZENG F, SCHNEIDER S, et al. Survivin as a therapeutic target for radiation sensitization in lung cancer. Cancer Res 2004; 64: 2840-2845. http://dx.doi. org/10.1158/0008-5472.CAN-03-3547

[33] IWASA T, OKAMOTO I, SUZUKI M, NAKAHARA T, YAMANAKA K, ET AL. Radiosensitizing effect of YM155, a novel small-molecule survivin suppressant, in non-small cell lung cancer cell lines. Clin Cancer Res2008; 14: 6496-6504. http://dx.doi.org/10.1158/1078-0432.CCR-08-0468

[34] VISAGIE MH, BIRKHOLTZ LM, JOUBERT AM. 17-betaestradiol analog inhibits cell proliferation by induction of apoptosis in breast cell lines. Microsc Res Tech 2014; 77: 236-242. http://dx.doi.org/10.1002/jemt.22334

[35] LANGSENLEHNER U, RENNER W, YAZDANI-BIUKI B, EDER T, WASCHER TC, et al. Integrin alpha- 2 and beta- 3 gene polymorphisms and breast cancer risk. Breast Cancer Res Tr 2006; 97: 67-72. http://dx.doi.org/10.1007/s10549-005-9089-4

[36] HOOD JD, CHERESH DA. Role of integrins in cell invasion and migration. Nat Rev Cancer 2002; 2: 91-100. http://dx.doi. org/10.1038/nrc727 
[37] HASEGAWA Y, TAKANASHI S, KANEHIRA Y, TSUSHIMA T, IMAI T, et al. Transforming growth factor- $\beta 1$ level correlates with angiogenesis, tumor progression, and prognosis in patients with nonsmall cell lung carcinoma. Cancer 2001; 91: 964-971. http://dx.doi.org/10.1002/10970142(20010301)91:5<964::AID-CNCR1086>3.0.CO;2-O

[38] SENGER DR, PERRUZZI CA, STREIT M, KOTELIANSKY VE, DE FOUGEROLLES AR, et al. The alpha(1)beta(1) and alpha(2)beta(1) integrins provide critical support for vascular endothelial growth factor signaling, endothelial cell migration, and tumor angiogenesis. Am J Pathol 2002; 160: 195-204. http://dx.doi.org/10.1016/S0002-9440(10)64363-5

[39] DING W, FAN X-L, XU X, HUANG J-Z, XU S-H, et al. Epigenetic Silencing of ITGA2 by MiR-373 Promotes Cell Migration in Breast Cancer. PloS One 2015; 10: e0135128. http://dx.doi.org/10.1371/journal.pone.0135128

[40] ZHAO W, WANG Y, WANG Y, GAO N, HAN Z, et al. Potential anti-cancer effect of curcumin in human lung squamous cell carcinoma. Thorac Cancer 2015; 6: 508-516. http://dx.doi. org/10.1111/1759-7714.12222

[41] MAMMOTO T, JIANG A, JIANG E, PANIGRAHY D, KIERAN MW, et al. Role of collagen matrix in tumor angiogenesis and glioblastoma multiforme progression. Am J Pathol 2013; 183: 1293-1305. http://dx.doi.org/10.1016/j. ajpath.2013.06.026
[42] COOLEY BC. Collagen-induced thrombosis in murine arteries and veins. Thromb Res 2013; 131: 49-54. http://dx.doi. org/10.1016/j.thromres.2012.09.019

[43] SZOT CS, BUCHANAN CF, FREEMAN JW, RYLANDER $\mathrm{MN}$. In vitro angiogenesis induced by tumor-endothelial cell co-culture in bilayered, collagen I hydrogel bioengineered tumors. Tissue Eng Part C Methods 2013; 19: 864-874. http:// dx.doi.org/10.1089/ten.tec.2012.0684

[44] LI L, FORMAN SJ, BHATIA R. Expression of DLK1 in hematopoietic cells results in inhibition of differentiation and proliferation. Oncogene 2005; 24: 4472-4476. http://dx.doi. org/10.1038/sj.onc. 1208637

[45] YIN D, XIE D, SAKAJIRI S, MILLER CW, ZHU H, et al. DLK1: increased expression in gliomas and associated with oncogenic activities. Oncogene 2006; 25: 1852-1861. http:// dx.doi.org/10.1038/sj.onc. 1209219

[46] YU F, HAO X, ZHAO H, GE C, YAO M, et al. Delta-like 1 contributes to cell growth by increasing the interferon-inducible protein 16 expression in hepatocellular carcinoma. Liver Int 2010; 30: 703-714. http://dx.doi.org/10.1111/j.1478-3231 $.2010 .02214 . \mathrm{x}$

[47] LI L, TAN J, ZHANG Y, HAN N, DI X, et al. DLK1 promotes lung cancer cell invasion through upregulation of MMP9 expression depending on Notch signaling. PLoS One 2014; 9: e91509. http://dx.doi.org/10.1371/journal.pone.0091509 